\title{
Síndrome de cauda equina por hematoma espinal post anestesia raquídea: reporte de caso
}

Pirez Gornatti V. ${ }^{1}$, Campos Silveira C. ${ }^{1}$, de Camargo Carotti A. ${ }^{1}$, Criscuolo Miksche L. ${ }^{1}$, Mateus Serzedo PS. ${ }^{1}$, Coelho Barroso F. ${ }^{1}$

1 Clínica de Anestesiología de Ribeirão Preto, Ribeirão Preto, Brasil.

Introducción: Los hematomas espinales son raros, pero pueden causar secuelas neurológicas permanentes si no se tratan de forma adecuada. Generalmente, ocurren en anestesias raquídeas con punciones traumáticas y múltiples. El diagnóstico y el tratamiento precoces son fundamentales para el buen pronóstico neurológico.

Caso clínico: Mujer, 64 años, hipertensa, tratada con losartan e hidroclorotiazida. Indicación quirúrgica de reparo de meseta tibial izquierda por fractura de tibia tras caída. En anticoagulación profiláctica con heparina de bajo peso, suspendida doce horas antes del procedimiento. Pruebas de laboratorio sin alteraciones. Realizada anestesia raquídea, $17 \mathrm{mg}$ de bupivacaina isobárica, aguja Quincke 25 Gauge, punción mediana única en L3-L4. La intervención duró 210 minutos. Luego, la paciente pasa a sala de recuperación post operatoria. Después de 3 horas, alta anestésica para enfermería sin quejas y AK 10 puntos. 10 horas después del alta anestésica presento anuria y pie caído bilateral, parestesia en cela y ausencia de reflejo cutáneo plantar bilateral. Realización de resonancia nuclear magnética, que mostro lesión compresiva subdural a la altura de la punción. Diagnosticado síndrome de cauda equina por hematoma subaracnoideo compresivo. Paciente encaminado para cirugía, laminectomía descompresiva, 18 horas después del inicio de los síntomas. En el primer post operatorio, resolución completa de la parestesia, aumento del grado de fuerza en miembros inferiores y control del esfínter urinario.

Discusión: El síndrome de cauda equina tiene una frecuencia aproximada de 0,1 en 10.000 bloqueos. Se relaciona con la vulnerabilidad de las fibras lumbosacras a grandes dosis de anestésicos locales y otras sustancias potencialmente neurotóxicas, como ser la sangre. La gravedad y extensión de la lesión son factores de incidencia en la recuperación, la demora en la intervención está relacionada con la persistencia de las secuelas. Los datos aún no son suficientes para indicar el mejor procedimiento para los pacientes. Una revisión de 647 casos muestra que la intervención quirúrgica fue más efectiva cuando en las primeras 6 horas del inicio de los síntomas, pero muestra no existir diferencia en los resultados cuando la intervención neuroquirúrgica ocurre después de 6 horas comparado al tratamiento conservador.

Conclusión: Es importante la práctica anestésica segura con el fin de perfeccionar la prevención de los hematomas y desarrollar la sensibilidad hacia el diagnóstico precoz. En cuanto, al tratamiento, todavía no hay datos que afirmen el mejor tipo de intervención.

https://doi.org/10.25237/congresoclasa2019.45 